\title{
The Relationship between Player's Value Systems and Their In-Game Behavior in a Massively Multiplayer Online Role-Playing Game
}

\author{
Chaoguang Wang and Gino Yu \\ Digital Entertainment Lab, Hong Kong Polytechnic University, Hung Hom, Kowloon, Hong Kong \\ Correspondence should be addressed to Gino Yu; gino.yu@polyu.edu.hk
}

Received 21 August 2017; Accepted 13 November 2017; Published 4 December 2017

Academic Editor: Hanqiu Sun

Copyright (C) 2017 Chaoguang Wang and Gino Yu. This is an open access article distributed under the Creative Commons Attribution License, which permits unrestricted use, distribution, and reproduction in any medium, provided the original work is properly cited.

\begin{abstract}
This study examines the relationship between player's value systems and their actions in playing a massively multiplayer online role-playing game. Online survey data from 1,577 players were paired with their behavioral metrics within the game. A number of correlations were found between the scores of value system and the in-game metrics. Participants that scored high on the Red value system tend to spend more real money in the game, level up their character and ability as quickly as possible, and seek other achievements in the forms offered by game world. These characteristics for fun, power, and immediate gratification are also predicted by the Red value system. The finding provides valuable information on how to better design, evaluate, and understand enjoyment in games. The results also show the possibility of using the game as a platform in inferring players' value systems and in training people to develop certain skills.
\end{abstract}

\section{Introduction}

MMORPGs (massively multiplayer online role-playing games) have become the most popular game genre, representing a revolution of social, cultural, and considerable financial impact. The total gaming market revenue of China increased to US $\$ 18.5$ billion in 2014, and MMORPGs accounted for about a third of it [1].

Understanding player characteristics is an essential part of game design and also has important implications for increasing games' potential for positive impact on society. The personality, which reflects the behaviors that define and characterize each individual, has been recognized as one of the key components to understanding both the uses and effects of video games. The diversity of player behaviors within game world also offers unique opportunities to study the relationship between personality and game playing, and MMORPGs are "a gold mine of personality data" [2].

However, the personality characteristics of players as a group are still not well understood, and there has been relatively little research involving personality of players and their in-game behavior. What is more, most of the current gaming research tends to be based on self-reported data obtained from the players using interviews, surveys, or ethnographic observations. To address these limitations, we should pay more attention to longitudinal data collected directly from games, which provides us with a solid empirical foundation to better understand these complex virtual worlds [3]. Studies about China MMORPGs players are also still scarce, and a better knowledge of them is to be hoped, given that China players are the largest MMORPGs user group in the world.

In the present study, we examine the relationship between player personalities as conceptualised by Graves [4] and their behavior in a MMORPG in China. The findings will help to gain insight about the audience in order to fulfil the needs of the specific player and enable game industry to create more engaging and targeted games.

1.1. Personality and Player Behavior. Personality is defined as the organized totality of characteristics or qualities that makes a person different from others. It combines attitudes, motivations, needs, and emotions and influences how people 
think, behave, and approach internal and external situations [5]. There have been numerous studies about the factors that may affect leisure activity of a given group, community, and population, such as age, education, income, sex, occupation, and social class [6]. However, for predicting leisure behavior, the traditional demographic variables have proven to be weak, and, as suggested before, personality may be a better predictor of choice than demographics for experiential products [7].

The response to video game is primarily based upon the relationship between the presentation of the game content and the interpretation occurring within the mind of the player. The personality has a strong influence on how people think and behave in the real world and should, therefore, also influence their in-game behavior as well. Existing research has also demonstrated players behaved much the same in online games as they do in the real world [8]. The patterns of neurons arising from virtual experiences are very similar to those arising from physical threats [9]. Since the players are personally invested in their avatars and the environment, the game playing is thought to be a personally revealing activity [10].

There have been a number of attempts to apply the personality to investigate playing styles of game users and explore the relationship between the personality and in-game behaviors. Using Myers-Briggs Type Indicator (MBTI) test, Bateman and Boon explored personality as a way to better understand game playing and how such information can affect game design [11]. In their research, 16 personality types of MBTI were grouped into four playing styles with different tastes and needs: conqueror, manager, wanderer, and participant. By conducting a Five-Factor Model personality test and a value survey, Griebel found both personality traits and values correlated with specific game play behavior in the game of Sims 2 [12]. Van Lankveld et al. correlated the game behavior within the game of Neverwinter Nights to scores in the personality questionnaire and demonstrated that all five traits of the Five-Factor Model have an effect on players' in-game behavior [13]. Tekofsky et al. investigated the correlations between Five-Factor Model personality traits and playing behavior of Battlefield 3 provided by a database of their game statistics and found that play style correlated significantly to players' personality [14].

The existing research has also revealed several meaningful correlations between personality traits and in-game behaviors in MMORPGs. Yee et al's study examined the link between personality and playing behaviors in World of Warcraft and found many behavioral cues in the game were related to personality traits of the Five-Factor Model [10]. For example, Extraverts prefer group activities over solo activities, and players that scored higher on Openness have more characters and complete more exploration achievements. In contrast, McCreery et al. found no significant correlations between Five-Factor personality traits and corresponding sets of in-game behavior in World of Warcraft, such as correlation between the Agreeableness trait and a set of predefined "agreeable" behaviors [15]. However, as acknowledged by McCreery et al., the validity of the behavior sets they defined was not analyzed, and it is not clear whether the items in each set form appropriate and reliable scales. Also the sample size $(n=39)$ in their study may be too small to have a generalized conclusion. In a more recent study, Worth conducted a survey on players' personalities of World of Warcraft and their different behaviors within the game [16]. Significant correlations were found between HEXACO (Honesty-Humility, Emotionality, Extraversion, Agreeableness, Conscientiousness, and Openness to Experience) personality traits and in-game behavior. For instance, Social Player-versus-Environment activities positively correlated with Extraversion.

In summary, a considerable amount of research about the player personality has narrowly focused on the horizontal psychological typologies, such as the Five-Factor Model. McLuhan stated that games are collective and social reactions to the main drive or action of a specific culture, and when cultures change, so do previously accepted patterns of games [17]. The horizontal psychological typologies, such as the Five-Factor Model, or the Myers-Briggs personality type system, merely identify stylistic differences and are unable to explain players' changing tastes in relation to their personality. There is a strong need to address the personality features of players using a developmental and hierarchical model. Additionally, the limited volume of research available for studying personality and in-game behavior overlooks more precise information related to game mechanics. Much research relied on self-edited game level or public database of game to record and analyze players' behavior but did not use commercial game data (also live player data sets).

\subsection{Value Systems Model and Measurement Instrument.} Graves performed decades of empirical research between the 1950 s and the 1970s regarding what is mature human personality and concluded with a framework of human development he named the Emergent Cyclical Levels of Existence Theory [4]. Graves' academic achievements were adapted to the model of Spiral Dynamics, the most authoritative theory on value systems, and introduced to a wider audience by his students and successors Beck and Cowan [18]. In the meantime, a considerable number of other studies and books have appeared, referring to Graves' model or Spiral Dynamics, and described a wide range of extensive applications in which the value systems could be used [19].

Graves pointed out that human nature is an open, constantly evolving system and humans construct new conceptual model of the world in response to the interaction of external conditions with internal neuronal systems [4]. Graves referred to these states of equilibrium between environmental problems of living and neurological coping systems as levels of existence or value systems. The value systems are the primary term we used here, which are considered to be modes of adjustment for coping with the perception of the reality of the world.

Graves identified eight core value systems consisting of a set of world views, a hierarchy of needs, and corresponding behavior. The development of value systems occurs in a fixed order as shown in Table 1. Each value system is designated by pairs of letters from Graves's original terminology, while the first letter stands for the neurological system and the second 
TABLE 1: Summary of value systems.

\begin{tabular}{|c|c|c|c|}
\hline Level and label & Means values & Nature of existence & Basic theme \\
\hline $\begin{array}{l}\text { 1th AN } \\
\text { (Beige) }\end{array}$ & None & Automatic & $\begin{array}{l}\text { Express self as if it were just another } \\
\text { animal according to the dictates of one's } \\
\text { imperative psychological needs }\end{array}$ \\
\hline $\begin{array}{l}\text { 2th BO } \\
\text { (Purple) }\end{array}$ & Traditionalism & Ttribalistic & Sacrifice self to the way of your elders \\
\hline $\begin{array}{l}\text { 3th CP } \\
\text { (Red) }\end{array}$ & Exploitation & Egocentric & $\begin{array}{l}\text { Express self, to hell with the } \\
\text { consequences, lest one suffer the torment } \\
\text { of unbearable shame }\end{array}$ \\
\hline $\begin{array}{l}4 \text { th DQ } \\
\text { (Blue) }\end{array}$ & Sacrifice & Deferentialistic & $\begin{array}{c}\text { Sacrifice self now in order to receive } \\
\text { reward later }\end{array}$ \\
\hline $\begin{array}{l}\text { 5th ER } \\
\text { (Orange) }\end{array}$ & Scientism & Materialistic & $\begin{array}{l}\text { Express self for what self desires, but in a } \\
\text { fashion calculated not to bring down the } \\
\text { wrath of others }\end{array}$ \\
\hline $\begin{array}{l}\text { 6th FS } \\
\text { (Green) }\end{array}$ & Sociocentricity & Personalistic & $\begin{array}{l}\text { Sacrifice now in order to get acceptance } \\
\text { now }\end{array}$ \\
\hline $\begin{array}{l}\text { 7th GT } \\
\text { (Yellow) }\end{array}$ & Accepting & Cognitivistic & $\begin{array}{c}\text { Express self for what self desires, but } \\
\text { never at the expenses of others and in a } \\
\text { manner that all life, not just my life, will } \\
\text { profit }\end{array}$ \\
\hline $\begin{array}{l}\text { 8th HU } \\
\text { (Turquoise) }\end{array}$ & Experiencing & Experientialistic & $\begin{array}{l}\text { Adjust to the realities of one's existence } \\
\text { and automatically accept the existential } \\
\text { dichotomies as they are and go on living }\end{array}$ \\
\hline
\end{tabular}

for the existential problems [4]. Beck and Cowan designated a different color for each value as symbol in their Spiral Dynamics Model, which has been widely accepted and used [18].

And, in the development process, the new value systems will merely establish subordination of the older ones, not eradicate them. For example, when the Purple system takes over, the Beige is still there and subordinated in it. The new value system includes and transcends the previous ones, thus forming a natural hierarchy, and there is a mixture of value systems at work in each person all the time.

As indicated by Graves, when in a certain development state, a human would have opened only certain systems for coping and has their own hierarchy of needs around a core value system [4]. They would think, feel, and be motivated in manners appropriate to the state of his centralization and have biochemical characteristics and a state of neurological activation particular to it.

Graves' theory has evident implication in the analysis of responses to video game, and its substance resides on revealing different sets of world views players place on their decisions and actions. What is more, Graves' theory suggested the value of individual is an evolving and always-open-tochange system, which moves beyond the assessment of fixed horizontal dimensions and type indicators of the individual personality. For example, according to Graves' model, we not only know that a person is operating on the Blue but that he came from the Red and could move up to the Orange. Compared with Five-Factor Model or other personality theory, this valuable information permits us to understand the player personality in relation to not only current game playing but also their changing tastes.
A number of efforts have been made to develop instruments for assessing a person's position in the levels of Human Existence hierarchy. The CultureView (http://5deepvitalsigns.com/products/instruments/cultureview-series/) is derived from the original work of Graves and built upon the work of Don Beck. It was developed and owned by Don Beck and originated in paper form in 1997. Beck first met Graves in 1975 shortly after his Emergent Cyclical theory was published in 1974. He worked with Graves closely until Graves' death in 1986 and then continued to spend many years adapting the work of Graves. CultureView developed by Don Beck, therefore, seemed one of the most qualified instruments to assess individual's value system based on Graves' theory. Since 2001, the CultureView instrument has over 12,000 electronic completions globally and has been translated to many different language versions including English (UK), Dutch, Korean, German, and Spanish.

\section{Methods}

With an innovative mixed methodology, this study brings together methodological approaches from self-report survey and game metric technique. Participants recruited from the game Ghost II firstly completed an initial survey about value systems and then the value profile was paired with their behavioral metrics within the game world.

2.1. Chinese Translation of the CultureView and Verification. We employed a Chinese translation of the CultureView to assess six value systems from Purple to Yellow. Table 2 lists a representative question of CultureView and illustrates how participants respond to it in a 7-point Likert scale. The 
TABLE 2: Representative statements of six value systems, from survey question of CultureView.

\begin{tabular}{|c|c|c|c|c|c|c|c|c|}
\hline \multicolumn{9}{|c|}{ What matters most to me... } \\
\hline Value systems & Representative statement & 1 & 2 & 3 & 4 & 5 & 6 & 7 \\
\hline Purple & $\begin{array}{l}\text { Be Safe by staying close to friends and } \\
\text { family }\end{array}$ & & & & & & & \\
\hline Red & $\begin{array}{l}\text { Be Strong by taking charge and calling } \\
\text { the shots }\end{array}$ & & & & & & & \\
\hline Blue & $\begin{array}{l}\text { Be Dependable by doing what is right and } \\
\text { responsible }\end{array}$ & & & & & & & \\
\hline Orange & $\begin{array}{l}\text { Be Successful by setting goals and getting } \\
\text { ahead }\end{array}$ & & & & & & & \\
\hline Green & $\begin{array}{l}\text { Be Sensitive by experiencing feelings and } \\
\text { promoting harmony }\end{array}$ & & & & & & & \\
\hline Yellow & $\begin{array}{l}\text { Be Authentic by integrating natural } \\
\text { functions and flows }\end{array}$ & & & & & & & \\
\hline
\end{tabular}

response options ranged from 1 (very disagreeable) to 7 (very agreeable).

After translating to Chinese, the CultureView was tested among people who can speak both fluent English and Chinese. 10 participants firstly completed the English or Chinese version randomly and then were invited to complete the other corresponding version. After each testing, the correlation was calculated between English and Chinese items, computing Pearson Correlation for the items of continuous variables and Chi-Square Tests for the items of nominal variables. If the result is not significant $(p>0.05)$, the translation of those items will be revised and be brought to one more tested again with another 10 participants. Totally, 4 sessions of testing were conducted to make sure that the item translated to Chinese is significantly correlated with the original English item.

The high correlation between Chinese and English items has indicated that we can retain the validity and reliability of the CultureView. The original CultureView is known to have high validity as verified by the expert review and shown through the personal interview in coaching process. We then examined the test-retest reliability of the Chinese version with 20 participants, and they completed the CultureView twice with an interval of one week. $87.65 \%$ of items were significantly correlated between two tests, showing a good reliability of the questionnaire. Finally, an online version of CultureView with Chinese items translated and tested was created and used to assess the value systems of Chinese players in the present study.

2.2. Ghost II. Ghost II (http://nie.163.com/en/qn2.html\#aw, NetEase Inc., China), a 3-dimension Real-Time MMORPG, is currently the widely popular online game available commercially in China. Early in 2011, just 131 days after it was released, the total number of registered players was announced as over 12 million. And Ghost II was ranked as one of the Top Ten Domestic MMORPGs in 2012 and 2013 by Chinese game media.

As shown in Figure 1, the game playing of Ghost II is designed around a huge number of different quests or raids, which refer to a specific in-game adventure or endeavor. There are countless objectives and game contents for players

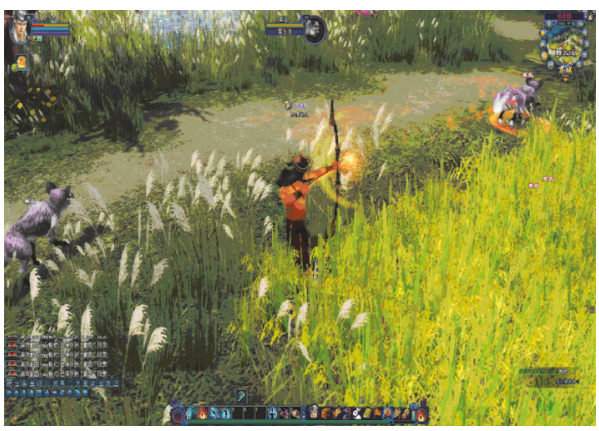

FIGURE 1: A screenshot of Ghost II.

to achieve and explore, such as getting to the next level, acquiring rare items, and being part of a story. Ghost II not only allows task related activities for achievement but also provides a rich context for social experience. Players are encouraged in different ways to communicate and collaborate with other players and regroup in massive guilds. PvP (playerversus-player) activities are also provided from one-to-one duels to large 20-versus-20 battlegrounds.

2.3. Administration of the Online Survey and Game Metric. With the permission of the NetEase Company that developed and runs Ghost II, the linkage of CultureView survey was presented to the player within the game world directly, and all data was automatically collected and stored via the online survey system of NetEase.

The data collection took place over a period of one week, and all respondents were not paid or compensated for their participation. As shown in Figure 2, when players first logged in during this period, a message appeared and invited them to complete the online survey. When clicking the link to the survey included in this message the participants were taken to a website to submit their data online. The message appeared only once and was not presented again when this character logged on next time. Also this research limited the survey and invitation message to characters above 15 levels in order to ensure we could gain sufficient information about in-game behavior from the higher level characters 
TABLE 3: In-game behavior in Ghost II.

\begin{tabular}{|c|c|c|}
\hline & Variables & Description \\
\hline$(1)$ & Time played & $\begin{array}{c}\text { Amount of time (minutes) logged onto the game since the character } \\
\text { was created }\end{array}$ \\
\hline$(2)$ & Consumption & $\begin{array}{l}\text { Amount of real money (China Yuan) spent in game for virtual items } \\
\text { since the character was created }\end{array}$ \\
\hline (3) & Character level & Level of current character \\
\hline$(4)$ & Magic stone level & Level of magic stone, an item for enhancing equipment \\
\hline$(5)$ & Character ability score & Reflecting comprehensive ability of character \\
\hline$(6)$ & Achievement Point & Total number of achievements player has completed \\
\hline$(7)$ & Ranking of ability among friends & Ranking among the friends list player added \\
\hline$(8)$ & Equipment score & Sum of all equipment item scores \\
\hline$(9)$ & Ability Practice & Number of times player has leveled up character skill and ability \\
\hline$(10)$ & Number of friends & Total number of present friends added \\
\hline$(11)$ & Goodwill point & Gaining through grouping and helping lower level player \\
\hline$(12)$ & Guild level & Level of guild belonged to \\
\hline$(13)$ & Guild point & Contribution to guild by finishing quest or activities \\
\hline$(14)$ & Dueling point & Number of winning in duel with players \\
\hline$(15)$ & Player killing point & Number of killing other player maliciously \\
\hline$(16)$ & Battleground score & $\begin{array}{c}\text { Gaining through Killing against other player and winning a battle in } \\
\text { battleground }\end{array}$ \\
\hline$(17)$ & Pet score & Pet is a little functional but largely decorative companion \\
\hline$(18)$ & House score & $\begin{array}{l}\text { Reflecting player house's construction that is mainly for decorating } \\
\text { and vanity }\end{array}$ \\
\hline$(19)$ & Narrative point & Count of completing main storyline quests \\
\hline$(20)$ & Marriage & Married or not \\
\hline$(21)$ & Mentorship & In a mentorship or not \\
\hline$(22)$ & Character Class & Character class participant chooses \\
\hline
\end{tabular}

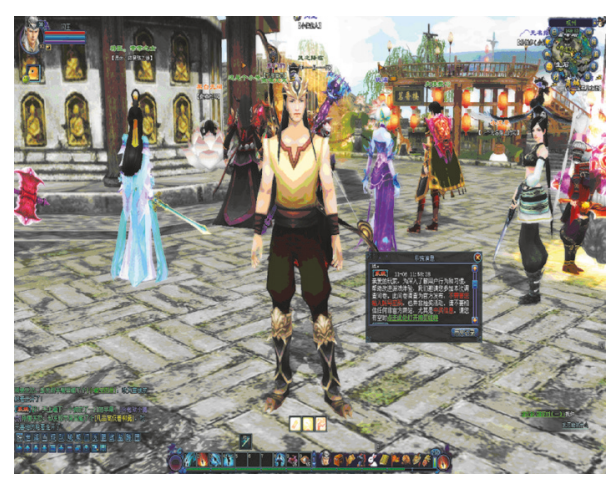

FIgURE 2: Survey Invitation Message in Ghost II.

and also not to interrupt the game play of new players. The data form collected in this study contained the following: items of CultureView questionnaire, gender, age, income, areas of residence, occupation, education background, character identity number of player, IP address of respondent, and completion time.

This research had access to the official database of Ghost II in order to collect data of the participant's actual in-game behavior. Player character ID was used as the key for game metrics retrieval, and the players' self-report data containing demographic and value system variables was paired with their character profile created by data mining. Overall, what a player says and does at all times is precisely recorded in MMORPGs, and we can track nearly all actions through the analysis of game logs. In addition, video games vary widely in terms of the kinds of game play and action they offer. However, we cannot extract all possible variables for analysis in this research, and a basic grasp of core game mechanics is necessary.

This study limits the game metrics to a meaningful and manageable subset of longitudinal behavioral data related to the core play dynamics of Ghost II. Like other MMORPGs, Ghost II is achievement oriented and the game design encourages players to progress, gain power, and accumulate wealth and status in game world. The in-game behavior data reviewed here was the key performance statistics of playing in Ghost II and also covered a wide range of behaviors, such as the character level, playing time, the quality of equipment, achievement score, the amount of PvP activities, friendship, and guild membership. A full list and description of the behaviors recorded and analyzed here have been presented in Table 3. All the metrics data recorded here were tracked since the character was first created and were cumulative over a long time. 
TABLE 4: Correlations between value systems and player behavior.

\begin{tabular}{|c|c|c|c|c|c|c|c|}
\hline & Variables & Purple & Red & Blue & Orange & Green & Yellow \\
\hline (1) & Time played & -0.003 & 0.036 & 0.047 & 0.005 & 0.036 & 0.020 \\
\hline (2) & Consumption by time & 0.041 & $0.101^{* *}$ & 0.035 & $0.090^{*}$ & 0.015 & 0.035 \\
\hline (3) & Character level & 0.017 & $0.064^{*}$ & 0.034 & 0.034 & 0.028 & 0.028 \\
\hline (4) & Magic stone level by time & 0.018 & $0.061^{* *}$ & -0.018 & 0.049 & -0.038 & 0.042 \\
\hline (5) & Character ability score & 0.011 & $0.063^{*}$ & 0.039 & 0.035 & 0.049 & 0.037 \\
\hline (6) & Achievement Point & 0.004 & 0.042 & 0.031 & 0.007 & $0.058^{*}$ & 0.026 \\
\hline (7) & Ranking by time & 0.000 & -0.014 & 0.007 & 0.010 & -0.027 & 0.036 \\
\hline$(8)$ & Equipment score by level & 0.020 & $0.050^{*}$ & 0.041 & 0.028 & $0.053^{*}$ & 0.034 \\
\hline (9) & Ability practice by time & 0.007 & $0.051^{*}$ & 0.011 & 0.047 & 0.047 & 0.007 \\
\hline (10) & Friends number by time & 0.013 & 0.007 & -0.008 & 0.023 & -0.033 & 0.016 \\
\hline (11) & Goodwill point by level & -0.007 & 0.017 & $0.064^{*}$ & 0.022 & 0.033 & 0.018 \\
\hline (12) & Guild level by level & 0.027 & 0.033 & 0.000 & 0.033 & 0.010 & 0.005 \\
\hline (13) & Guild point by level & 0.009 & -0.011 & 0.013 & 0.034 & -0.025 & -0.005 \\
\hline (14) & Dueling point by time & 0.021 & 0.022 & 0.017 & 0.037 & -0.002 & 0.014 \\
\hline (15) & Killing point by time & 0.015 & 0.023 & -0.015 & 0.013 & -0.024 & -0.005 \\
\hline (16) & Battleground score by time & 0.002 & 0.018 & -0.015 & -0.006 & -0.010 & -0.004 \\
\hline (17) & Pet score & 0.010 & $0.061^{*}$ & 0.031 & 0.042 & 0.047 & 0.043 \\
\hline (18) & House score by level & 0.018 & 0.018 & 0.021 & 0.000 & $0.056^{* *}$ & 0.021 \\
\hline (19) & Narrative point by level & -0.006 & $0.053^{* *}$ & 0.015 & 0.017 & 0.029 & 0.007 \\
\hline$(20)$ & Marriage & -0.012 & -0.015 & 0.004 & 0.018 & -0.024 & 0.010 \\
\hline$(21)$ & Mentorship & -0.020 & -0.019 & -0.013 & -0.017 & 0.010 & 0.017 \\
\hline
\end{tabular}

Notes. ${ }^{*} p<0.05 .{ }^{* *} p<0.01$.

\section{Results}

3.1. Participant Demographics. The majority of respondents $(58.8 \%, n=1,577)$ are male, and over one-third of them (36.5\%) are aged between 19 and 22 years, and $29.5 \%$ study for or achieved a bachelor degree. Overall, $28.2 \%$ of participants registered as a full-time student, 7.6\% worked in technology or research occupations, $5.9 \%$ worked in sales occupations, and $5.7 \%$ worked in production occupations. $31.1 \%$ of them earned no monthly income, and $23.4 \%$ had a monthly income between 3,001 and 5,000 RMB (China Yuan).

Most participants had extensive prior experience with online games. More than 40 percent had played online game over 4 years, $18.1 \%$ from 2 to 3 years, and $16.1 \%$ from 3 to 4 years. The game experience of participants covered nearly all popular MMORPGs available in the Chinese market. Prior to Ghost II, over 10 percent played League of Legends mostly, 9.1\% played Fantasy Journey to the West 2 mostly, $8.3 \%$ played CrossFire mostly, and about 5 percent played World of Warcraft mostly.

3.2. Correlation Analysis between Value Systems and In-Game Behavior. The game metrics need to be normalized. For example, a player who played for one year would spend more money in the game than a player who played just three months. But there was not one variable that all metrics could be normalized against. Most in-game behaviors were normalized against the time played, including consumption, magic stone level, ability practice, number of friends, dueling point, player killing point, battleground score, ranking of ability among friends, and guild point. Some metrics that were highly dependent on character level were normalized against character level accordingly, such as equipment score, house score, goodwill point, narrative point, and guild level. For example, a level 60 character can be easily accepted as a member by a higher level guild than a level 20 character. For metrics that could not be normalized, their original numbers were calculated, including character level, character ability score, achievement point, pet score, marriage, mentorship, and class.

A series of Pearson's $r$ correlation tests was performed between scores on the six value systems measured by CultureView and 15 continuous player behavior variables recorded by game metrics. Pearson's $r$ analysis was also applied to determine the correlations between the score of value systems and 2 dichotomous variables of marriage and mentoring relationship of players, since we can use Pearson's $r$ to calculate point biserial correlation. Table 4 lists the total number of significant correlations per value system. The correlations with $p<0.05$ are considered to be significant.

The significant results revealed by value systems will be described in the following sections. No significant correlations were found between in-game behavior and scores on the Purple or Yellow value systems, all $p>0.05$.

3.2.1. Red. Of the six value systems measured here, Red provides the most and strongest correlations with in-game behavior of the player. As defined by Graves, the theme of Red state is to express self and to hell with the consequences. The people operating at the Red level are "egocentric, impulsive 
TABLE 5: Multiple regressions on six value systems.

\begin{tabular}{lcccrc}
\hline Variables & $R$ & $R^{2}$ & Adjusted $R^{2}$ & $F$ & 0.775 \\
Purple & 0.074 & 0.005 & -0.002 & 2.328 & 0.666 \\
Red & 0.128 & $\mathbf{0 . 0 1 6}^{* *}$ & 0.009 & 0.007 \\
Blue & 0.092 & 0.009 & 0.002 & 0.221 & 0.438 \\
Orange & 0.130 & $\mathbf{0 . 0 1 7 ^ { * * }}$ & 0.010 & 1.126 & 0.005 \\
Green & 0.089 & 0.008 & 0.001 & 0.336 \\
Yellow & 0.081 & 0.007 & 0.000 & 0.932 \\
\hline
\end{tabular}

Notes. ${ }^{* *} p<0.01$.

and hedonistic" and "for him the best answer to any problem is the one that brings him immediate pleasure regardless of what happens to anyone else" [4]. The motivation is for power, fun, and control, and the belief is "might-isright."

Players who scored high on Red tend to advance in the game as quickly as possible. They spent more real money to buy in-game items (2), which is the main indicator of devotion to the game for a free-to-play game. Their character level (2) increases gradually with the scoring on the Red. They had a higher magic stone level (4) and equipment score (8), showing that they seek to become powerful and acquire rare items that other players may never have. The magic stone is a core game mechanic of Ghost II, which can be used to level up the property value of equipment and items, and so contributes a lot to promote the total ability of the character. Players can buy magic stones by paying real money directly within the game and can also acquire them through completing some quests and raids.

Such players enjoy making constant progress and gaining priority in the forms offered by the game. They completed a higher number of ability practices (9), and their ability score (5) was also high, which means they spent a lot of time and money to improve or optimize their own character. They completed the main storyline and gained more narrative points (19), which can be used to level up present skills or acquire new skills. They even had a high score on their pet (17), which provides some help in fighting but mainly as a customization.

3.2.2. Blue. The primary value of the Blue state is to sacrifice now to get reward later. People here control their impulses and easily defer to a higher authority. They also follow certain rules which are considered to offer a clear sense of right and wrong.

Individuals who scored high on the Blue value system gained more goodwill points (11), which is a reward for grouping with a lower level player and helping them to kill monsters or complete quests.

3.2.3. Orange. According to Graves' model, the people of Orange state seek self-achievement and try to find the best solution through rational thought. They value the accomplishments and enjoy the process of competition.

In terms of game playing performance, the individual who scored high on the Orange value system also spent more real money within the game (2). No other significant correlations were found between Orange score and other achievement indicators of virtual behaviors such as character level or equipment score.

3.2.4. Green. As seen by Graves, in the Green state, people are concerned with inner peace and group recognition. They are derived by the need for community, equality, and unity. Individuals that scored high on Green had a high score of achievement points (6) and equipment (8), showing they have a diversity of interests within game. They were also attracted by the house system (18) of the game, which is mainly used for customization and display purpose.

Beside the correlation analysis, the impact of character class on value systems was assessed using a one-way analysis of variance (ANOVA). The analyses revealed that there was a significant difference on the score of Red across ten character classes, $F=1.90, d f=9, n=1,577$, and $p=0.048<0.05$. For example, Swordsman scored highest on the Red followed by the archer; both are classes of material attack.

The correlation coefficient, such as Pearson's $r$, only reveals the relationship between two variables, and a multiple regression could allow us to better examine the value system in its relation to more than one behavioral variable. Six linear multiple regressions were conducted on each of the value systems with 11 behavioral variables as predictors that correlated significantly with value system. We used an Entry method, which forces all 11 predictor variables into the model simultaneously. As the results in Table 5 indicate, the multiple regressions for Red $(p<0.01)$ and Orange $(p<0.05)$ were significant, and the other four regression models were not significant.

It is suggested that we can infer a player's Red or Orange value system statistically using playing behaviors in the game world. For instance, the best predictor of Red value system was the magic stone level $(\beta=3.10, p<0.001)$ followed by the total consumption $(\beta=2.77, p<0.005)$. However, the regression value is low, and only $1.6 \%$ of variance in Red or $1.7 \%$ of variance in Orange scores can be predicated by 11 playing behavioral variables.

\section{Discussion}

Through pairing players' value systems from self-report data with their actual behaviors recorded by game metrics, we explore and explain the relationships between value systems and playing behavior in a MMORPG. To date, the current study is the first attempt to investigate the links between 
Graves' construct and players' in-game behavior. With this work, we show that there is a correlation between in-game behavior and real-life behavioral attitudes as modeled by the ECLET. Participants that scored high on the Red value system tend to spend more real money in the game, level up their character and ability as quickly as possible, and seek other achievements in the forms offered by game world. These characteristics for fun, power, and immediate gratification are also predicted by the Red value system. The results also show the possibility of using the game as a platform in inferring players'value systems.

A number of significant correlations were observed between the score of value systems and the in-game metrics. The consumption in the game has a positive relationship with Red and Orange, which means that increases in the scores of those two value systems correspond to more real money spent for the virtual items contained within Ghost II. Both Red and Orange value systems are viewed as externally oriented (expression self to control the world) and strive for self-achievement, and so, a possible explanation for them purchasing virtual items is that the items give users a performance advantage. As shown by other researchers, there is a link between the virtual item purchases with real money and motivations of playing for advancement and advantage in competitive settings and self-expression, and enhancing playing performance is regarded as the main driver of realmoney spending in games [20].

There is also a positive relationship between goodwill points (gained through grouping with players who are 15 levels lower than themselves) and the Blue value system, where higher scoring of Blue corresponds to an increase in helping others. A key characteristic of Blue value system that seems to be supported by this preference is caring about other people and giving support. Both achievement points and house score have a positive relationship with the Green value system. Regarding the positive relationship of achievement points, the people that scored higher on Green have a wide range of different interests because the achievement point is the sum of total achievements of leveling up characters, completing quests, competing with others, making friends, joining guilds, and exploring new maps. Such players also show interest in the house system which has more decorative value than functional value. All these suggested that players who scored higher on Green (internally oriented) pay more attention on their own inner interest and uniqueness as anticipated by the ECLET.

We find that up to eight playing behaviors are positively correlated with the score of Red value system, which accounted for the largest number of significant relationships between the value system and playing features, covering nearly all key game performances from consumption, character level, magic stone, character ability, equipment, ability practice, and pet system to narrative points. This finding reveals that the Red value system is the most important one to explain and anticipate game playing. Players who scored high on the Red value system tend to commit a considerable amount of money on the game, seek powerful items and equipment, and level up their character and skills as quickly as possible. Beck and Cowan previously noted that video games are a safe place where the Red can go for fun and adventure [18] because the game environment allows them to behave as they would normally do in real life and create a scenario with settings that support who they are and how the world works for them. The features of the Red value system, such as preferring instant gratification, valuing violence, and no sense of shame, match the core play dynamics of video games well, where advancement, competition with monsters or other players, impatience, and impulsive reactions are presented and reassure the behaviors, feelings, and tendencies of Red value. As we discovered here, only significant relationships between Red and achievement within the game were found, and no significant links were observed between Red and social interaction or casual playing such as making friends, joining guilds, and pet or house system.

Content personalization and system customization based on a user's personality factors have long been interests of the game development [21]. This finding has important implication for game design, since it provides valuable information for game designers to understand and meet the need of target users as accurately as possible. The links between value systems and online consumption can be applied to the designing of virtual items that ultimately generate the revenues for the game and help to determine who would potentially be the customer for the virtual items in question and how to better satisfy their needs and wants. This has become a main concern of game designers and player model research [22]. For example, for the user that scored high on Red, the virtual goods should be presented in a simple, concrete, and visual manner. The short-term benefits they will bring immediately must be stressed.

Another possibility directly applicable to game design would be to use inferred learning styles of players as modeled by their certain value system to minimize the learning curve involved to master game play. Every game starts with a training session in which the participants learn how to perform the various actions that are necessary to play the game. The design of these tutorials is essential for retaining new users and, to a certain extent, can determine the success of a commercial game. As is shown above, the players express more characteristics of Red value system within their game playing. As maintained by Graves, the people operating at the Red state cannot learn by punishment, because they do not feel or comprehend punishment [4]. They find their way through learning only by positive reinforcement, and the learning takes place best when the reward is presented soon after they do what we want them to do. As for designing game tutorials, we should not give any punishment such as death of character or deduction of experience points if an error is made by the new player. Designers should simply ask the player to start again until the desired operation is achieved and then award them immediately. Also, the individuals tend to have a very short attention span, and you must have everything structured [4]. The tutorials design should ensure every minute is laid out and always put something in front of a player in order to hold them right there. They move from a 60 -second playing session to the next playing session and if there is any pause in this flow, it will distract their attention and they may leave the game. 
Except for feeding the industry, the long term implications of this research will be huge. The results show the possibility of inferring users' value systems based on their activity traces within the game. Traditional personality assessment methods such as behavioral measurement, observation, and questionnaire may suffer from many weaknesses including ambiguity, high cost, and reliability. The games could be used as an alternative method of establishing personality profiles of the individual [13]. Video game combined the strengths of traditional personality assessment tools by quantifying behavior, automating observations and side-stepping selfreport, and, what is more, it offered a high ecological validity [14]. Yee et al. believed that MMORPGs are a platform to develop unobtrusive personality assessment tools [10].

The game experience can also be further used to facilitate personal transformation on their level of existing as defined by Graves, while game content can engage the user's awareness and belief. Griebel indicated that skills used in a virtual world would be naturally translated into real lives of players and suggested that the game might be a useful instrument in training people to develop certain skills [12]. And role-play games are considered to be particularly effective in exploring individual's personal development. As admitted by Graves, the difficulty in training the Red man is that we do not have someone there to "give them an immediate reward when they do what we want them to do" [4]. But, in a digital game, players can be rewarded immediately once they achieve the goal set by the game designer. Instead of placing the individual in potentially mortal danger, the game will highlight the underlying negative belief structures in a safe way. By storing awareness acquired through game experience, individuals can slightly moderate their future value system and world view in real world situations which have the same underlying structure and pattern.

The findings indicate that the value system is only moderately related to their playing features within game. We noted the correlations calculated here are low, and, according to the effect size classified by Cohen, most of our findings would be "small effect" $(r \leq 0.10)$ [23]. Although statistical relations were obtainable, the personality of a player may be at best one variable among many that needed to be considered for explaining gaming behavior.

However, the effect sizes of our findings are of enough magnitude and are equal to or greater than the effect sizes reported in other similar research. Yee discovered that over 60 percent of significant correlations between scores on five personality traits of FFM with behavior variables in World of Warcraft were at $r<0.10$ with only three correlations with $r>0.15$. For example, the number of deaths in dungeons correlated significantly with score on Extraversion at $r=$ 0.06 [10]. In line with this, Tekofsky et al. noted almost all significant correlations they revealed between the 100 IPIP (International Personality Item Pool) scores of FFM and the 173 playing behavior variables in Battlefield 3 have a small effect size of $r<0.1$, and only the 17 correlations were at 0.10 $<r<0.15$ among all 4,442 significant correlations yielded in their result [14]. Harari et al. investigated whether avatars in World of Warcraft convey information about players' personalities and observed very weak relations $(r=0.03)$ [24].

There are multiple sources that influence players' actions within a game, including peer pressure, previous experience, time available, friendship, and cultural background. Higher effect sizes may be found between personality and playing behavior in future study if we take into account more variables and have a better controlled experiment process. The small effect sizes of correlations may be partly due to the large sample size of present research, while the research conducted with small sample has lower statistical power and often yields higher effect sizes. To sum up, even though at first sight the correlations revealed might be seen as low, considering the broader complexity involved here, thus the proportions covered by value system factors should not be minimized.

One major limitation of the present study is that the results may be slightly biased by recruiting participants and gaining metrics from only one game. It is unclear whether the relationship we found here can also be generalized to other game players. More studies are recommended to gather data from additional games to increase the generalization. Another limitation may be the bias of cultural influences, since only the data of Chinese players was collected [25]. In any future study, it would be helpful to do a cross-cultural comparison within game players. And, finally, we relied on the set of variables that Ghost II recorded. It is possible that other unrecorded variables, such as logged chat, may be even more predictive of value systems.

\section{Conflicts of Interest}

The authors declare that there are no conflicts of interest regarding the publication of this paper.

\section{References}

[1] China gaming industry report (Abstract), (2014), accessed 18th May 2015, http://cdn.cgigc.com.cn/report/2014/game_report_ 2014_brief.pdf.

[2] N. Yee, "The psychology of MMORPGs: Emotional investment, motivations, relationship formation, and problematic usage," in Avatars at Work And Play: Collaboration and Interaction in Shared Virtual Environments, vol. 34, pp. 187-207, SpringerVerlag, London, UK, 2006.

[3] S. De Castell, N. Taylor, J. Jenson, and M. Weiler, "Theoretical and methodological challenges (and opportunities) in virtual worlds research," in Proceedings of the 2012 Foundation of Digital Games Conference, FDG 2012, pp. 134-140, USA, June 2012.

[4] C. W. Graves, The Never Ending Quest, ECLET Publishing, Santa Barbara, CA, USA, 2005.

[5] W. Mischel, Y. Shoda, and R. E. Smith, Introduction to Personality: Toward an Integration, John Wiley and Sons, New York, NY, USA, 2004.

[6] G. Bammel and L. L. Burrus-Bammel, Leisure and Human Behavior, Brown and Benchmark, Madison, WIS, USA, 3rd edition, 1996.

[7] L. A. Barnett, "Accounting for leisure preferences from within: The relative contributions of gender, race or ethnicity, personality, affective style, and motivational orientation," Journal of Leisure Research, vol. 38, no. 4, pp. 445-474, 2006. 
[8] F. Bayraktar and H. Amca, "Interrelations between virtualworld and real-world activities: Comparison of genders, age groups, and pathological and nonpathological internet users," Cyberpsychology, Behavior, and Social Networking, vol. 15, no. 5, pp. 263-269, 2012.

[9] J. Blascovich and J. Bailenson, Infinite Reality: Avatars, Eternal Life, New Worlds, and the Dawn of the Virtual Revolution, William Morrow and Co, New York, NY, USA, 2011.

[10] N. Yee, N. Ducheneaut, L. Nelson, and P. Likarish, "Introverted elves \& conscientious gnomes: The expression of personality in World of Warcraft," in Proceedings of the 29th Annual CHI Conference on Human Factors in Computing Systems, pp. 753762, 2011.

[11] C. Bateman and R. Boon, 21st Century Game Design (Game Development Series), Charles River Media, Cambridge, Mass, USA, 2005.

[12] T. Griebel, "Self-portrayal in a simulated life: Projecting personality and values in the sims 2," Game Studies, vol. 6, no. 1, article no. $5,2006$.

[13] G. Van Lankveld, P. Spronck, J. Van Den Herik, and A. Arntz, "Games as personality profiling tools," in Proceedings of the 2011 7th IEEE International Conference on Computational Intelligence and Games, CIG 2011, pp. 197-202, Republic of Korea, September 2011.

[14] S. Tekofsky, P. Spronck, A. Plaat, J. Van Den Herik, and J. Broersen, "Play style: Showing your age," in Proceedings of the 2013 IEEE Conference on Computational Intelligence in Games, CIG 2013, Canada, August 2013.

[15] M. P. McCreery, S. Kathleen Krach, P. G. Schrader, and R. Boone, "Defining the virtual self: Personality, behavior, and the psychology of embodiment," Computers in Human Behavior, vol. 28, no. 3, pp. 976-983, 2012.

[16] N. C. Worth and A. S. Book, "Personality and behavior in a massively multiplayer online role-playing game," Computers in Human Behavior, vol. 38, pp. 322-330, 2014.

[17] M. McLuhan, Understanding Media: The Extensions of Man, MIT Press, London, UK, 1st edition, 1994.

[18] D. E. Beck and C. Cowan, Spiral Dynamics: Mastering Values, Leadership and Change, Blackwell Publishing, Malden, MA, USA, 1996.

[19] K. Wilber, A Theory of Everything, Shambhala, Boston, Mass, USA, 2001.

[20] V. Lehdonvirta, "Virtual item sales as a revenue model: Identifying attributes that drive purchase decisions," Electronic Commerce Research, vol. 9, no. 1-2, pp. 97-113, 2009.

[21] C. T. Tan and H.-L. Cheng, "Tactical agent personality," International Journal of Computer Games Technology, Article ID 107160, 2011.

[22] J. Hamari and J. Tuunanen, "Player Types: A Meta-synthesis," Transactions of the Digital Games Research Association, vol. 1, no. 2, 2014.

[23] J. Cohen, "A power primer," Psychological Bulletin, vol. 112, no. 1, pp. 155-159, 1992.

[24] G. M. Harari, L. T. Graham, and S. D. Gosling, "Personality Impressions of World of Warcraft Players Based on Their Avatars and Usernames: Consensus but No Accuracy," International Journal of Gaming and Computer-Mediated Simulations, vol. 7, no. 1, pp. 58-73, 2015.

[25] C. Wang and G. Yu, "The relationship between players value systems and their In-game behavior in a massively multiplayer online role playing game," in Proceedings of the 2nd Annual Conference of Chinese DiGRA, Beijing, China, 2015. 


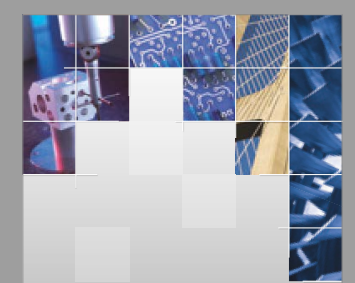

\section{Enfincering}
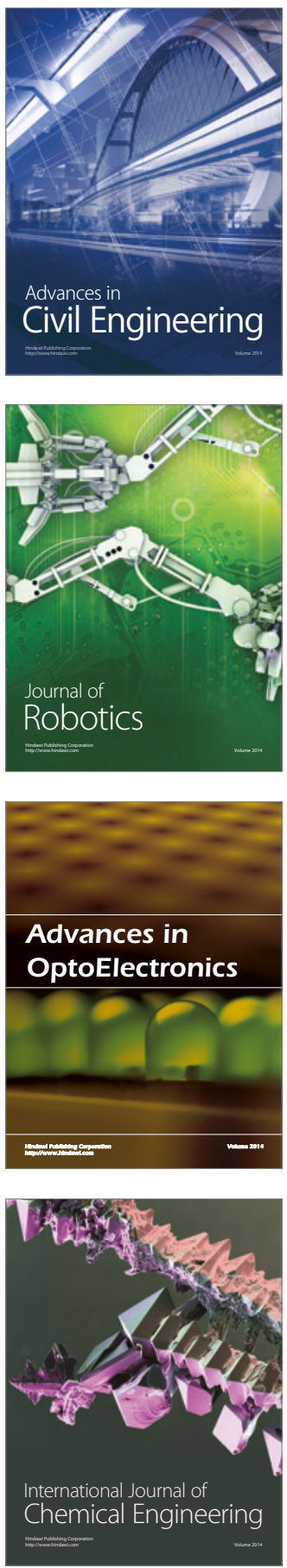

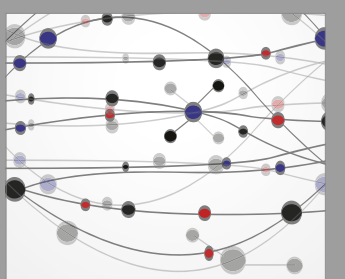

The Scientific World Journal

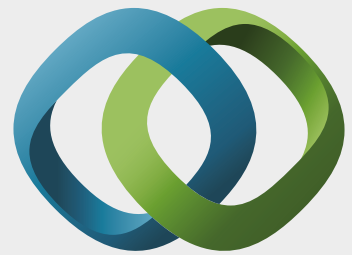

\section{Hindawi}

Submit your manuscripts at

https://www.hindawi.com
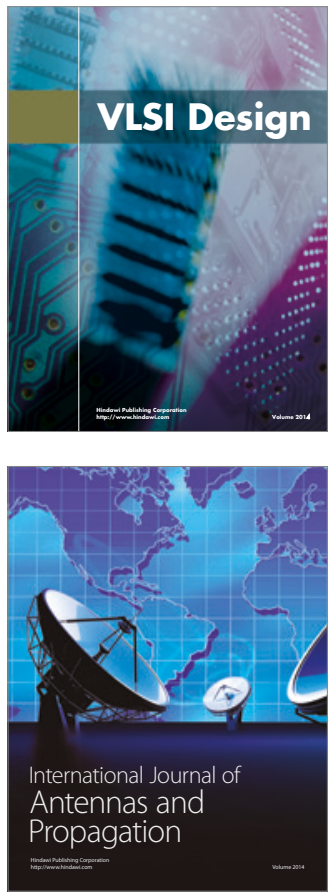

\section{Rotating}

Machinery
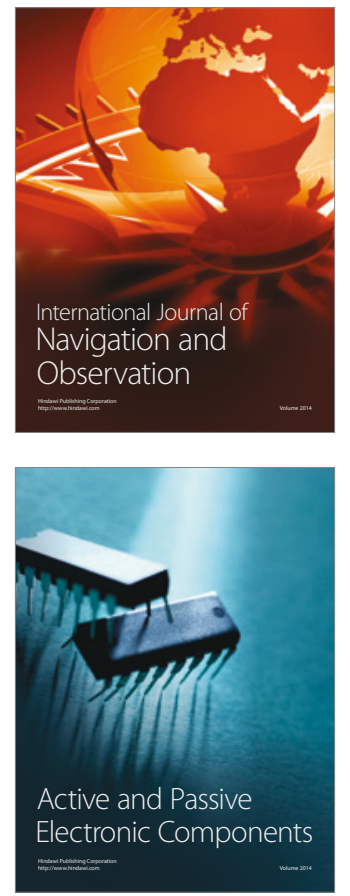
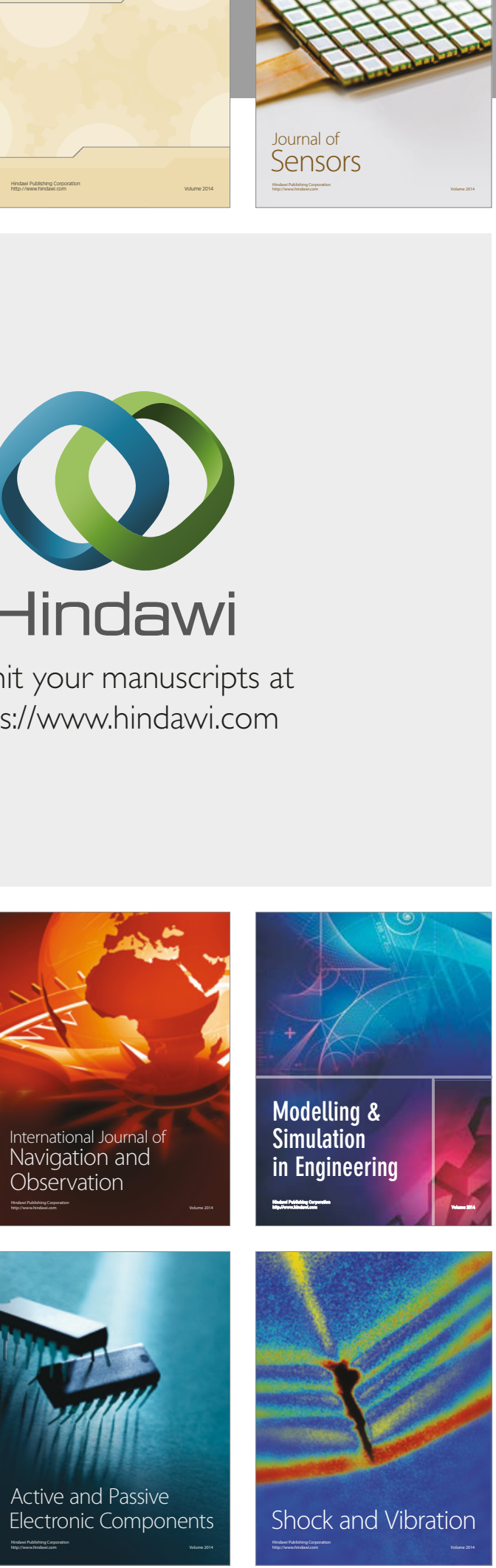
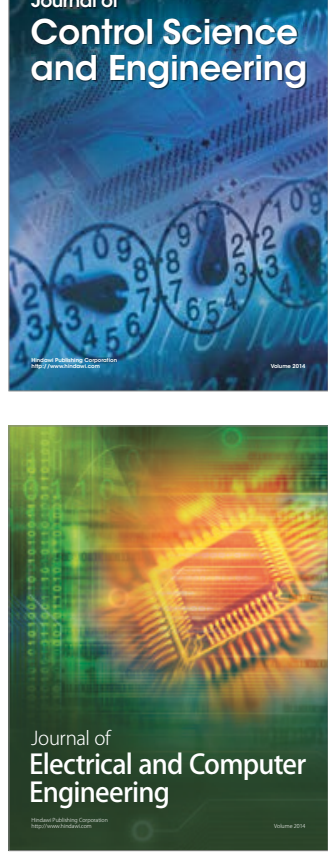

Distributed

Journal of

Control Science

and Engineering
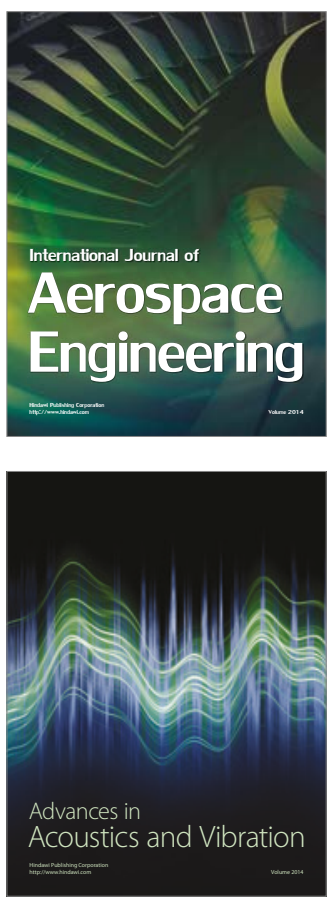

Sensor Networks 